\title{
Therapieausfall = Minusstunde?
}

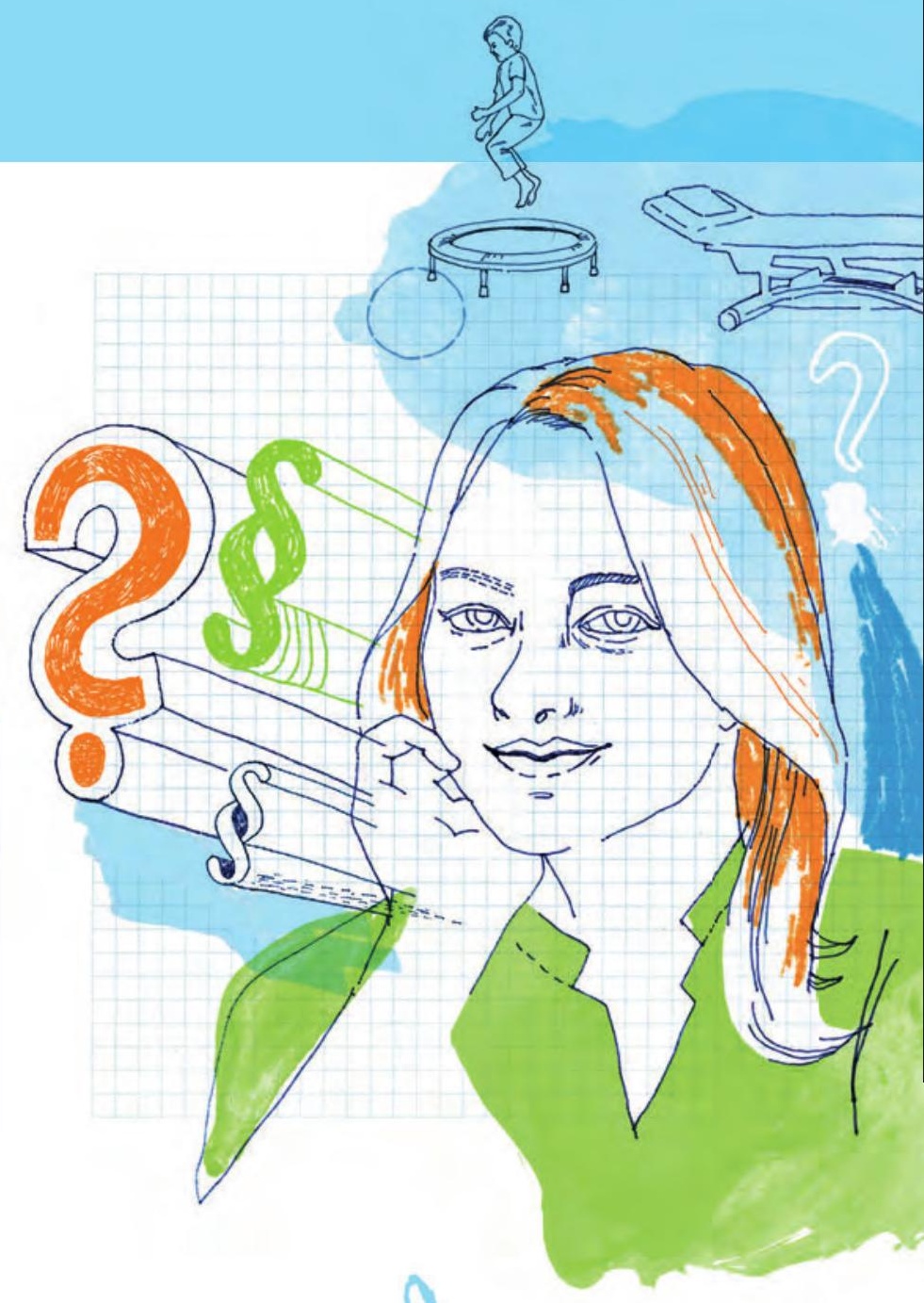

\section{Die Antwort unseres Experten}

Ein Arbeitgeber verfügt über das Direktionsrecht. Das heißt, er kann bestimmen, was sein Mitarbeiter wann und wo tut. Hierbei ist er aber nicht frei, sondern muss nach „billigem Ermessen“ entscheiden und darf den Arbeitnehmer nicht benachteiligen. Er muss dessen Interessen berücksichtigen, ist aber zum Beispiel nicht an Wünsche zur Arbeitszeit gebunden.

Begrenzt wird das Direktionsrecht durch Regelungen im Arbeitsvertrag und durch Gesetze. Sieht der Vertrag beispielsweise eine 40-Stunden-Woche vor, kann der Arbeitgeber nicht ohne weiteres verlangen, dass sein Mitarbeiter mehr als 40 Stunden arbeitet. Enthält der Vertrag keine Vereinbarung über die täglich abzuleistenden Stunden, könnte ein Chef bis zu 10 Stunden Arbeit zuzüglich der Pausen verlangen. Ob am Ende eines solch ausgereizten Arbeitstages noch Therapieerfolge zu erwarten sind, steht auf einem anderen Blatt. Die vereinbarten 40 Stunden pro Woche kann der Arbeitgeber theoretisch so aufteilen: an zwei Tagen je neun Stunden, an zwei je sieben Stunden und an einem Tag acht Stunden. Eine erheblich längere Arbeitszeit muss der Arbeitgeber rechtzeitig ankündigen, eine geringere kann er kurzfristig anweisen.

Das bedeutet, dass ein Chef, der auch Zeitpunkt und Dauer einer Pause vorgeben darf, bei Ausfall einer Therapieeinheit eine Pause oder früheren Feierabend anweisen könnte. Das führt evtl. zu Minusstunden. Innerhalb der 40-Stunden-Woche kann er an einem anderen Tag zum Ausgleich mehr Arbeit verlangen, damit das „Soll“ erreicht wird. Ist in der Woche nicht genug Arbeit vorhanden, darf der Arbeitgeber verbleibende Minusstunden nicht einfach in die Folgewoche mitnehmen. Er muss dann die im Vertrag vereinbarten 40 Stunden bezahlen, auch wenn die Therapeutin nur 35 gearbeitet hat. Eine Ausnahme besteht nur, wenn Arbeitnehmer und Arbeitgeber die Mitnahme der Minusstunden vereinbart haben. Weit verbreitet ist das sogenannte Arbeitszeitkonto. Es dient in der Regel als Guthabenkonto, kann aber auch mit Minusstunden geführt werden. Hat ein Angestellter
Arbeitszeitguthaben angesammelt und fällt dann an einem Tag weniger Arbeit an, kann der Arbeitgeber diese „Minusstunden“ mit dem Guthaben auf dem Arbeitszeitkonto verrechnen. Bezahlt wird dann ebenfalls die vereinbarte Wochenarbeitszeit.

Bei einer freien Mitarbeiterin stellt sich das Problem mit den Minusstunden nicht. Sie trägt das Risiko eines Arbeitsausfalls in der Regel selbst, da sie nur die tatsächliche Leistung vergütet bekommt. Wird sie aber von der Praxis für konkrete Arbeitszeiten angefordert, hat sie auch dann Anspruch auf die Vergütung, wenn keine Patienten zu behandeln sind und sie in der Zeit auch keine anderen Arbeiten erbringen kann.

Im Ergebnis kommt es also auf die konkreten Vereinbarungen zwischen Arbeitnehmer und Arbeitgeber an, ob Therapieausfall als Minusstunde angerechnet werden kann.

Karsten Bossow

\section{$\Rightarrow$ Wirft auch Ihr Berufsalltag rechtliche Fragen auf? Dann schreiben Sie an Simone.Gritsch@thieme.de.}

